\title{
Active crack control in continuously reinforced concrete pavements (CRCP)
}

\author{
Pieter De Winne ${ }^{1}$, Hans De Backer ${ }^{2}$, Sien Depuydt ${ }^{3}$
}

${ }^{1}$ Visiting Professor, Dept. of Civil Engineering, Ghent University, Technologiepark Zwijnaarde 904, B-9052 Zwijnaarde (Ghent), Belgium; email: p.dewinne@ugent.be

${ }^{2}$ Professor, Dept. of Civil Engineering, Ghent University, Technologiepark Zwijnaarde 904, B-9052 Zwijnaarde (Ghent), Belgium; email: hans.debacker@ugent.be

${ }^{3}$ Master of Science in Civil Engineering, Ghent University

\begin{abstract}
Continuously reinforced concrete pavements (CRCP) are frequently used in Belgium on roads having heavy traffic because they have a better long-term performance and require low maintenance. Free cracking is allowed in CRCP but the cracking pattern is controlled by the continuously longitudinal reinforcement. The problem is that in reality the crack pattern is not as desired. Distances between cracks are sometimes smaller, creating clusters of cracks. These clustered cracks can evolve over time, and, after many heavy axle load passages, lead to destructive punch-outs.

To obtain a uniform crack pattern, the active crack control technique tries to force the cracks to originate in the young concrete at regular distances, perpendicular to the axis of the road. This is done by making some saw cuts in the new pavement, within 24 hours after placement, along the side of the CRCP slab.

This research study tries to find the optimal dimensions of the saw cuts which result into a uniform crack pattern. To do this, a numerical 2D model of a road segment is made with the finite element program Samcef Field. The length between the notches (= saw cuts) and the width and depth of the saw cuts are varied and deformations and stresses in the concrete and reinforcement are compared. The same is done for a 3D model which is generated based on the 2D model.

The results from the parameter study show that the dimensions of the active crack control technique applied nowadays, i.e. saw cuts of $40 \mathrm{~cm}$ long, $4 \mathrm{~cm}$ deep, every $1.20 \mathrm{~m}$, works properly.
\end{abstract}

Keynotes: continuously reinforced concrete pavement, active crack control, finite element modelling, tensile stresses

\section{INTRODUCTION}

With active crack control one tries to force the position of the cracks in the young CRCP by making some cuts in the road, where the cracks will then originate.

In current tender specifications (SB250 2016), the saw cuts are made on one side of the concrete lane, perpendicular to the axis of the road, with a length of $40 \mathrm{~cm}$ and a depth of $4 \mathrm{~cm}$. The distance between the notches is $1.20 \mathrm{~m}$. The saw cuts are applied immediately 
after the exposed aggregate finishing of the surface and within 24 hours of laying the concrete. This may be done manually with a cutting disk.

The question is how the crack pattern changes if one or more dimensions of the saw cut are adjusted and if one is able to find the optimal dimensions.

\section{D MODEL}

The two-dimensional finite element model is based on the model of Choi et al. (2011). First, a basic element is modelled, which will be developed at a later stage to a 3D model that takes into account the complete shape of the saw cuts. Cracks in concrete appear when the tensile stress is larger than the tensile strength.

The model is started from a concrete element between two complete cracks with a saw cut in the middle. One steel bar is also modelled. The model is drawn in the XZ plane. The length of the element is following the $\mathrm{X}$-axis, the height is drawn according to the Zaxis and the width is along the Y-axis. A general view is shown in Figure 1.

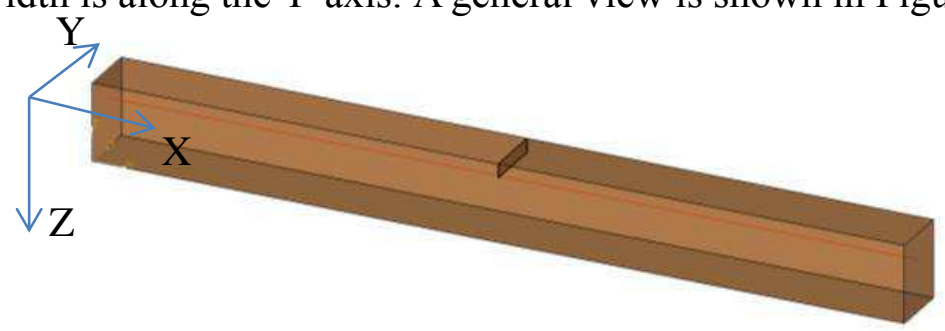

Figure 1. General view of basic model.

Because the length between two cracks is $1.2 \mathrm{~m}$, the total length of this element is thus $2.4 \mathrm{~m}$. The height of the element is $23 \mathrm{~cm}$ according to the tender specifications used in Belgium since 1995. In this case, a 2D study is performed so actually there is no width, but as the program expects a width, a width of $180 \mathrm{~mm}$ is chosen. This is the distance between two longitudinal reinforcement bars. The reinforcement has a concrete cover of $8 \mathrm{~cm}$, so it is placed at a height of $15 \mathrm{~cm}$ measured from the bottom of the element.

The saw cut has a depth of $40 \mathrm{~mm}$, a width of $3 \mathrm{~mm}$ and a length of $180 \mathrm{~mm}$. Normally the length of the notch is $400 \mathrm{~mm}$, but as only a section with a width of $180 \mathrm{~mm}$ is generated, the length of the saw cut is taken equal to this $180 \mathrm{~mm}$ and is thus considered over the total width of the element.

The material characteristics can be found in Table 1 .

Table 1. Material characteristics used in the model.

\begin{tabular}{lcc}
\hline & Concrete & Steel \\
\hline Thermal expansion coefficient & $12.10^{-6} \mathrm{~m} / \mathrm{m} \cdot \mathrm{K}$ & $12.10^{-6} \mathrm{~m} / \mathrm{m} \cdot \mathrm{K}$ \\
Young's modulus & $40600 \mathrm{~N} / \mathrm{mm}^{2}$ & $210000 \mathrm{~N} / \mathrm{mm}^{2}$ \\
Poisson's ratio & 0.2 & 0.3 \\
Mass density & $2500 \mathrm{~kg} / \mathrm{m}^{3}$ & $7850 \mathrm{~kg} / \mathrm{m}^{3}$ \\
\hline
\end{tabular}


As a 2D model is considered, the displacements out of the plane (in the direction of the $\mathrm{Y}$-axis) need to be restricted. Because rotations around the $\mathrm{X}$ - and $\mathrm{Z}$-axis cause displacements out of the plane, they need to be restricted as well.

At the sides where the reinforcement bar goes through (at the left and right side of the element in Figure 1), there is a vertical crack over the total height of the concrete. This means that the concrete can shrink without any problems, but it cannot expand because of the surrounding concrete. The upper side of the concrete is in contact with the air so there are no constraints needed. Horizontal and vertical displacements as well as rotations can appear. The lower side of the concrete is in contact with the bottom layer. This contact causes friction when horizontal displacements occur. This effect is taken into account with horizontal springs. In the basic model the springs are only applied in the X-direction. The value for the spring constant is assumed to be $0.041 \mathrm{MPa} / \mathrm{mm}$ according to Choi et al. (2011). The curvature effect in combination with a vertical support of the ground is implemented with vertical springs. The vertical springs have a value of $0.09 \mathrm{MPa} / \mathrm{mm}$, which is equal to the mean bedding constant of a highly compacted sand ground.

The bond between the steel and the concrete is modelled with "bushings" in Samcef Field. Because a bushing averages its reaction forces over its length, the rod and the concrete element have to be divided in smaller parts to obtain more accurate results. With a bushing, one part of the steel bar is connected with the surrounding part of the concrete. It is chosen to work with a cylindrical frame with an axial and radial stiffness. The value for the axial stiffness is found by multiplying the horizontal stiffness according to Choi et al. (2011), 193.2 MPa/mm, with the mantle surface of the steel rod. The radial stiffness is given a value of $1012 \mathrm{~N} / \mathrm{mm}$.

Only the effect of a temperature difference is being examined. The loads of vehicles are not considered. As concrete is much stronger for pressure caused by a positive temperature gradient, it is important to look to the other situation: strain caused by a negative temperature gradient. The temperature difference is considered uniform in the longitudinal direction and is taken as $-25^{\circ} \mathrm{C}$.

Because it is important to have detailed results in the area of the saw cut, the mesh needs to be made finer in that area and weird mesh shapes need to be avoided. This is accomplished by using a progressive distribution of the mesh nodes in this area. The distance between the mesh nodes in the area of the crack is $5 \mathrm{~mm}$ and increases to $45 \mathrm{~mm}$ further away (see Figure 2). Due to this mesh constraints, tetrahedra are formed.

\section{STRUCTURAL ANALYSIS}

Displacements. In Figure 2 the total displacements of the basic model are shown. Due to the negative temperature gradient, the concrete shrinks instead of expanding. The middle part stays more or less at the same place, but the sides are pushed into the ground. This is possible because of the springs modelled in the ground. The largest displacements are found at both sides of the element where the concrete has cracks over the complete 
height. The maximum displacement is $0.60 \mathrm{~mm}$, which is definitely not large, so to interpret the crack behaviour it will be more useful to look to the stresses in the concrete.

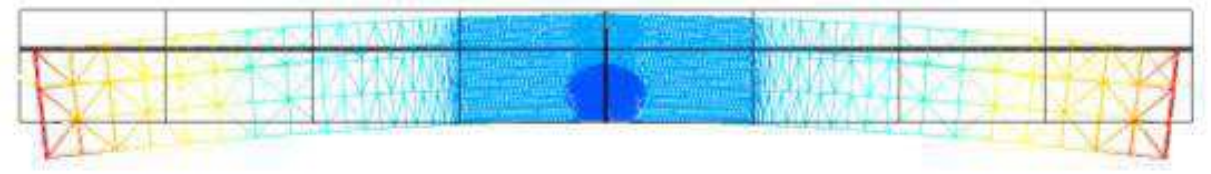

Figure 2. Total displacements in basic element.

Concrete stresses. The applied concrete quality has a minimum average compressive strength of $70 \mathrm{~N} / \mathrm{mm}$. The corresponding mean axial tensile strength is $4.61 \mathrm{~N} / \mathrm{mm}$. The stresses found with Samcef Field (see Figure 3) are compared to these values.

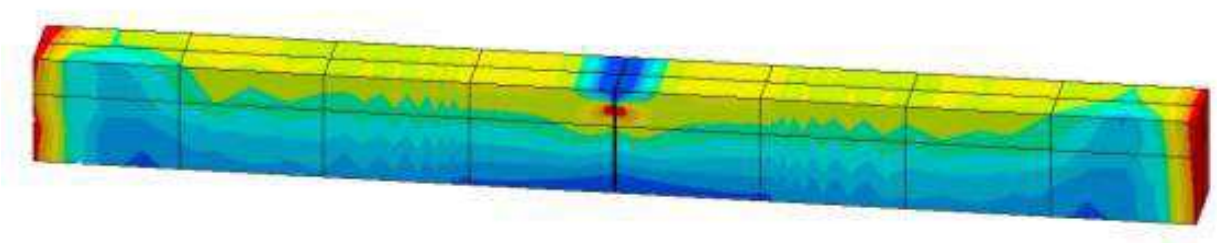

\section{Figure 3. First principal stresses in the basic element with a length of $2.4 \mathbf{~ m}$.}

The interpretation of the stresses is not as easy as expected. First of all some random peak values of high stresses appear at the level of the saw cut in the concrete. One need to be careful with evaluating these peak stresses, because they are related to the applied mesh size. Irregular mesh elements and nodes containing to many mutual mesh elements can cause stress peaks, which do not exist in reality.

Secondly, it is important to know in which direction the stresses are oriented. As this element is much longer in the $\mathrm{X}$-direction than in the $\mathrm{Y}$-direction and the movements in the Y-direction are restricted because of a $2 \mathrm{D}$ interpretation, the stresses in the $\mathrm{X}$ direction need to be much higher than in the Y-direction. In interpreting stresses it is also important to look to the principal stresses. In this case, the first principal stresses are more or less the same as the stresses in the X-direction due to its $2 \mathrm{D}$ character.

The last remark that can be made is that the tensile stresses at both sides of the element at the level of the cracks are very high. This is because of the boundary conditions, which restrict movements in the Y-direction. In the case of the current stress-analysis, these results can be neglected and only stresses in the area of the saw cut need to be considered.

In the area close to the saw cut, the highest stresses occur under the saw cut, as expected. It is also clear that a bifurcation-phenomenon occurs. This is normal in stress patterns at the location of cracks and it shows that the model works properly. At the surfaces next to the notch, the stress is zero, because the edges can move freely and no constraints are put on the surfaces at those locations.

Figure 4 shows the tensile stresses immediately below the saw cut, at intermediate vertical distances of $10 \mathrm{~mm}$. At the level of the saw cut (distance from saw cut $=0 \mathrm{~mm}$ ) 
the stresses are very high. In the next point, $10 \mathrm{~mm}$ under the bottom of the notch, the stress decreased to half of the stress at the saw cut. In the graph this shows up as a steep initial slope. For the next two points, at $20 \mathrm{~mm}$ and $30 \mathrm{~mm}$ respectively, the slope is more gradual. At the level of the reinforcement bar, $80 \mathrm{~mm}$ below the surface, a stress peak shows up. This is logical as the steel bar is bond to the concrete and friction occurs between the steel and the concrete when the concrete deforms, causing higher stresses. Going downwards from this point the stresses in the concrete are very low and they decrease gradually to zero towards the bottom.

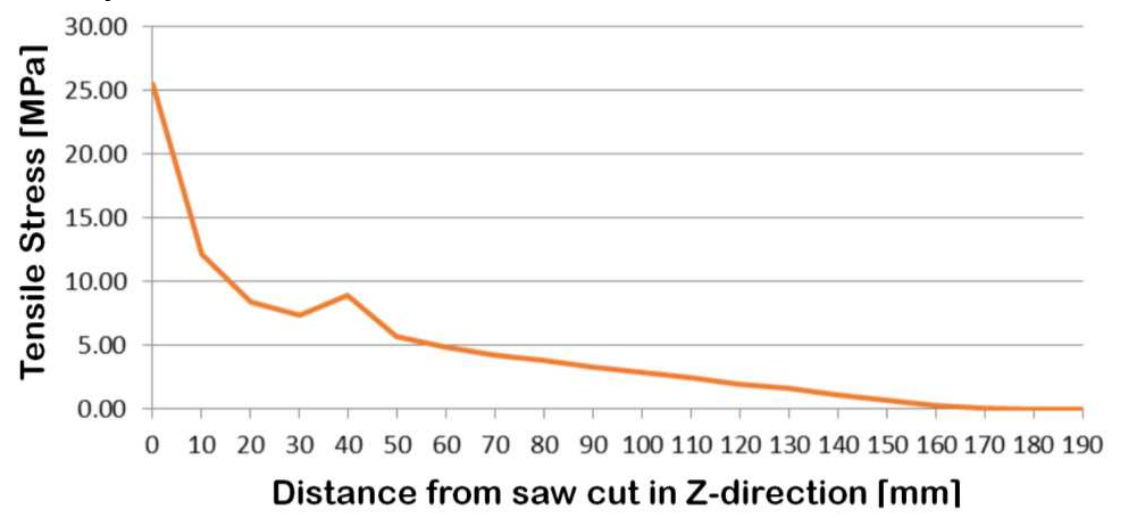

Figure 4. Tensile stresses under saw cut for basic model.

The stresses in the area between a crack at the side face and the saw cut are also high, but as the stresses under the saw cut are the highest, cracks will initially arise at that location and one expects that the concrete completely cracks at the saw cut. When this happens, the other stresses will decrease, so no additional cracks are formed in between the cracks originated by the saw cuts.

Steel stresses. As structural steel S500 with a characteristic yield strength of $500 \mathrm{~N} / \mathrm{mm}$ is used, the design yield stress is $435 \mathrm{MPa}$. The maximum value of the stresses at the ends of the reinforcement bar is $333 \mathrm{MPa}$. This value is lower than the yield stress of the steel, which is good and will not cause any problems.

\section{PARAMETER STUDY}

Length between the saw cuts. Keeping the saw cut width and depth constant and equal to the values in the basic model, different models are made to investigate the influence of changing the length between the saw cuts on the tensile stresses.

Models with a distance between the saw cuts of $0.6 \mathrm{~m}, 0.8 \mathrm{~m}, 1.0 \mathrm{~m}, 1.4 \mathrm{~m}, 1.6 \mathrm{~m}$ and 1.8 $\mathrm{m}$ are generated and the deformations and stresses are examined. The tensile stresses under the notch for these models are represented in Figure 5.

The stresses immediately under the saw cut are higher for the models with a longer distance between the saw cut. So one can expect that the optimal distance between the saw cuts is $1.2 \mathrm{~m}$ or longer. To see if additional cracks form in the middle of the element, elements with a total length of $1.4 \mathrm{~m}$ and $1.6 \mathrm{~m}$ are generated. So one assumes that the 
concrete cracked completely over the height at the location of the saw cut. The tensile stresses at the surfaces of both elements are larger than the tensile strength of the concrete. This means that additional cracks will form in the middle of the elements next to the required cracks. Consequently, the formed crack pattern is far from the designed crack pattern because of its too short crack distances. This can be a risk for punch-outs. One can conclude that the distance of $1.2 \mathrm{~m}$ between the saw cuts, like in the basic model, is the optimal distance between the saw cuts.

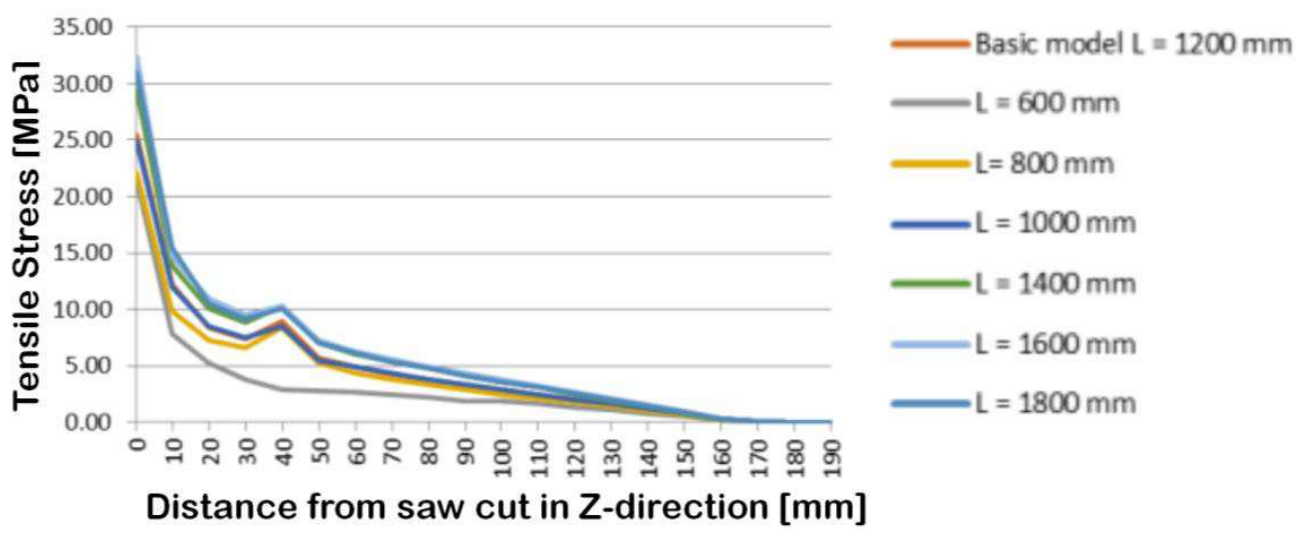

Figure 5. Tensile stresses for models with different lengths between saw cuts.

Width of saw cut. It is clear that the width of the saw cut is determined by the cutting disk of the sawing machine. Nowadays a sawing machine with a cutting disk of $3 \mathrm{~mm}$ is usually used. Models with a saw cut width of $1 \mathrm{~mm}, 5 \mathrm{~mm}, 7 \mathrm{~mm}$ and $10 \mathrm{~mm}$ are generated and the deformations and stresses under the saw cut for these models are examined. Changing the width of the crack doesn't influence the displacements at all. For the model with a narrower saw cut, the stresses are higher and for the wider saw cut, the stresses are lower. This is logical because sharp edges influence the magnitude of the stress values at the crack. The smaller the cut, the sharper the form and the higher the stresses will be. As there is no big difference in the stresses under the saw cut for the different models, one needs to choose the right sawing machine on the basis of logical thoughts. The bigger the width, the more risks there are for water and dirt accumulation, which can cause corrosion. So to avoid this, a small saw cut is desired. A smaller saw cut has the advantage of higher stresses directly below the saw cut as well. As a result, one can conclude that the supposed saw cut width of $3 \mathrm{~mm}$ is very good. A sawing machine with a thinner cutting disk can also be used.

Depth of saw cut. For many years, the required minimum depth according to researchers was $1 / 3$ rd or $1 / 4$ th of the slab thickness. But according to Zollinger et al. (1994), deep cuts made many hours after concrete placement are often less effective in controlling random cracking than shallow cuts made earlier. His argument is that the shallower saw cut takes advantage of the significant changes in moisture and temperature conditions at the surface of the slab to help initiate cracks at the tip of the saw cuts (Ren 2015). One 
also needs to take into account that the reinforcement is placed at a depth of $8 \mathrm{~cm}$, so when the saw cut is made too deep, the reinforcement bar will be damaged.

Taking into account the boundary conditions described above, models with a depth of 2 $\mathrm{cm}, 3 \mathrm{~cm}, 5 \mathrm{~cm}, 6 \mathrm{~cm}$ and $7 \mathrm{~cm}$ are generated and the deformations and stresses under the saw cut are compared with the basic model. The deeper the saw cut is made, the higher the displacements and the stresses in the concrete. The crack will originate much faster when the saw cut is made deeper. But as the concrete cover of the reinforcement bar is much lower in that case, risks of water and dirt infiltration and hence corrosion need to be taken into account. One can conclude that a deeper saw cut will give the desired crack pattern faster than with a more shallow saw cut. But to know which consequences this deep saw cut has on the violation on the steel bar and the concrete, experience is needed. Out of the experiments done on the E313 in Belgium, it is clear that the saw cut timing plays an important role in the effectiveness of the crack induction at the saw cut. The most beneficial conditions to induce cracks at the notches are a larger saw cut depth and earlier saw cutting.

\section{D MODEL}

The 2D model discussed in the previous paragraphs is extended to a $3 \mathrm{D}$ version. In fact, four of the basic elements are glued to each other in the Y-direction. So it is again a concrete element between two cracks with a saw cut in the middle. But there are some differences. Transverse reinforcement is added, so a steel grid is formed. The transverse rods have a diameter of $12 \mathrm{~mm}$ and are placed every $600 \mathrm{~mm}$. Furthermore, in this model, the total length of the saw cut is modelled. In Figure 6 the general view of the 3D model is shown. The thick black lines represent the reinforcement bars, the other lines are edges of the concrete element.
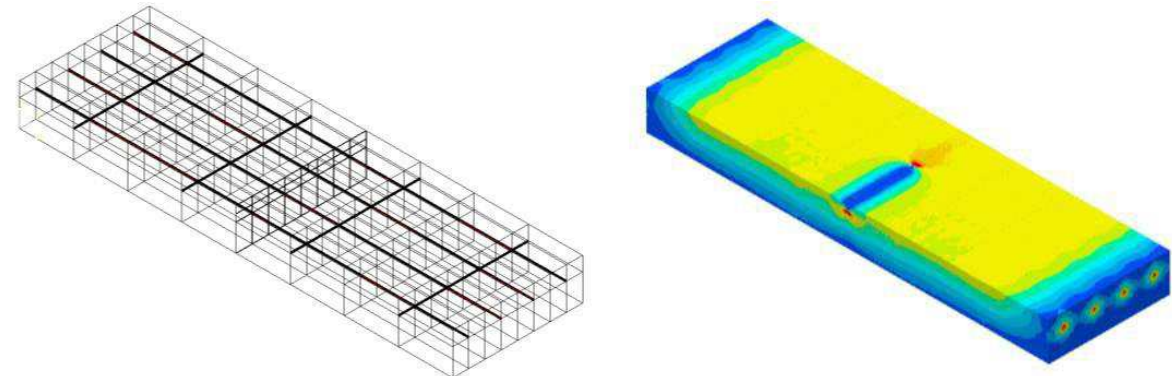

Figure 6. General view 3D model.

The displacements in the 3D model are almost the same as in the 2D model. The model shows exactly the behaviour for what it is designed. The highest stresses show up around the saw cut. There is an area of high stresses under the saw cut, just like in the 2D model, which will initiate the crack to grow further downwards. Other stress peaks are located at the end of the saw cut, at the surface of the concrete element. These stresses will force the concrete to crack there and to grow further over the width of the concrete to the opposite side. 
Changing saw cut length. A qualitative analysis of the influence of the adaption of the length is done for a model with a smaller notch length of $200 \mathrm{~mm}$ and one with a longer notch length of $600 \mathrm{~mm}$. The displacements and stresses in the models are compared with the results of the basic 3D model. The longer the notch length, the bigger the area of high stresses under the notch and at the end of the notch at the concrete surface. So because of the larger area of peak stresses, the easier and faster the crack origination can be expected.

\section{ADDITIONS AND REMARKS ON THE MODELS}

Early-age behaviour. In reality, the notches in the concrete pavement are made between 24 and 36 hours after construction. At these early ages, the tensile strength is still developing and does not have its final strength as assumed in the numerical model.

Non-linear temperature profile. In reality, when the temperature fluctuation at the pavement surface is compared with the one at the bottom, higher temperatures are observed at the surface. This is in contrast with the uniform temperature gradient put as load in all the models examined before.

Saw cut model. As the saw blade is circular, the end of the notch (with which one means the end "in" the pavement) does not have a flat face but a curved face (Ren 2015).

\section{CONCLUSION}

The results from the parameter study are quite positive and show that the active crack control technique applied nowadays works properly. It seems that the actual length between the saw cuts $(1.20 \mathrm{~m})$ is well chosen. The saw cut width of $3 \mathrm{~mm}$ gives good results as well. Based on the parameter study the depth $(4 \mathrm{~cm})$ and length $(40 \mathrm{~cm})$ of the notch would be chosen larger, but because the saw cuts are applied within 24 hours after construction, this is not necessary.

\section{REFERENCES}

Choi S., Ha S. and Won M. (2011). "Horizontal cracking of continuously reinforced concrete pavement under environmental loadings" in Construction and Building Materials Volume 25, Issue 11, 4250-4262.

Ren D. (2015) "Active Crack Control for CRCP" in doctoral thesis "Optimisation of the crack pattern in continuously reinforced concrete pavements", ISBN 978-94-6186579-3, Delft University of Technology, 155-210.

SB250 (Flanders tender specifications, Standaardbestek 250 versie 3.1). (2016) "Hoofdstuk 6, § 1.3.3.10 Actieve scheuraanzet voor doorgaand gewapend beton", 14-15.

Zollinger D., Tang T. and Xin D. (1994). "Sawcut Depth Considerations for Jointed Concrete Pavement Based on Fracture Mechanics Analysis," in Transportation Research Record, Issue 1449, 91-100. 